\title{
Achieving sustainable development of a company through digital transformation of the recruitment process
}

\author{
Natalya Nagibina ${ }^{1, *}$, Elena Kandybina ${ }^{1}$, Lyudmila Komyshova ${ }^{1}$, and Kirill Sclyarov ${ }^{1}$ \\ ${ }^{1}$ Voronezh State Technical University, Moscovskiy prospect, 14, Voronezh, 394026, Russia
}

\begin{abstract}
The recruitment process is of fundamental importance for any modern company, as provides the organization's need for personnel at various levels and contributes to its sustainable development. In the digital economy, it inevitably transforms and acquires a number of features, which determines the relevance of the research. The aim of the study presented is to consider the digital transformation of the company's personnel selection process in order to achieve its sustainable development. The research was performed in the framework of a systematic approach involving the use of methods of analysis, synthesis, observation and sociological methods. The article is devoted to the process of staff recruitment on the example of two organizations. In the first company, its implementation is carried out in a customary way, in the second - via a specialized software product. Based on the results achieved, the distinctive features of the considered processes are determined. It is concluded that it is impossible to develop any standard in this case. Attention is drawn to the different implementation of the considered personnel selection processes. Their advantages and disadvantages are highlighted.
\end{abstract}

\section{Introduction}

Depending on the level of the selected staff and the specifics of a company itself, the recruitment process may include a different number of stages (or selection steps), employees of the organization participating in the recruitment, and personnel selection methods that allow the employer to determine the applicant's compliance with the stated requirements.

However, the implementation of the process itself is undergoing significant changes in the digital economy. The digital transformation of the personnel selection process is aimed at ensuring the sustainable development of business entities, which is clearly demonstrated by the examples of the companies involved in the study.

Any company needs staff, so the recruitment process can be considered as a factor in achieving its sustainable development. In modern conditions of digitalization of activities, personnel selection acquires fundamental features, which determines the relevance of the

\footnotetext{
${ }^{*}$ Corresponding author: nagibina.natalya@yandex.ru
} 
study presented, the purpose of which is to consider the digital transformation of the recruitment process for a company to achieve its sustainable development.

\section{Materials and methods}

Methods of comparison and system analysis, methods of mathematical forecasting, system approach, and sociological methods were used as the research techniques. The validity of the recommendations and conclusions obtained due to the study involves the use of a set of methods by means of the sequential implementation of a range of activities and measures.

\section{Results}

In «Rosgosstrakh» LLC, the recruitment process of insurance agents involves the following selection steps [1].

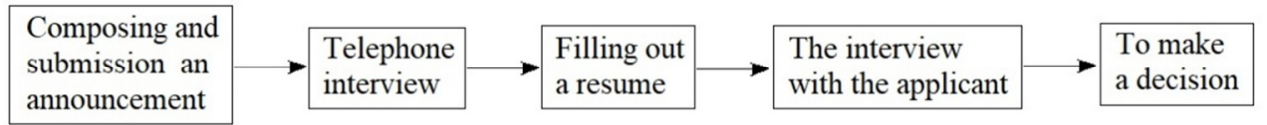

Fig. 1. Stages of hiring insurance agents for «Rosgosstrakh» LLC.

The step-by-step selection scheme involves a recruitment specialist, who is joined at the last stage by the Head of the structural division of the company, which the insurance agent is hired for.

The organization used ads in universities, print media, the Internet, and TV as sources for attracting job seekers.

The vacancy announcement allowed the applicants to leave their information in the form of a resume by the specified email or arrange a further interview by phone, which was the next step of the recruitment system.

The schedule of phone interviews was compiled by a recruitment specialist based on the received resumes and it was recorded on paper.

Applicants who were interviewed by phone filled out a resume form with information about their education, work experience, professional skills and previous job positions. In addition, photocopies of confirming documents were attached to the form. This information could be exchanged both on paper and through electronic means of communication.

The obtained materials and data were analyzed by a recruitment specialist and applicants who met the requirements were invited to an individual interview.

At each stage of the personnel selection process, the recruiter quantified (on a ten-point scale) such qualities of applicants as professional and communication skills, personal qualities, appearance and manners, performance and motivation, if the information provided such an opportunity. The points scored by the applicant were recorded in the evaluation sheet presented in table 1 .

Table 1. Evaluation list of the applicant for the position of insurance agent.

\begin{tabular}{|l|c|c|c|c|}
\hline Evaluated characteristics & $\begin{array}{c}\text { Resume } \\
\text { analysis }\end{array}$ & $\begin{array}{c}\text { Profile } \\
\text { analysis }\end{array}$ & Interview & Average mark \\
\hline Professional skills & 10 & 8 & 7 & 8.3 \\
\hline Communication skills & - & - & 9 & 9 \\
\hline $\begin{array}{l}\text { Personality traits of } \\
\text { character }\end{array}$ & 8 & 9 & 10 & 9 \\
\hline Appearance and manners & - & - & 9 & 9 \\
\hline Efficiency & 8 & 8 & 7 & 7.7 \\
\hline
\end{tabular}




\begin{tabular}{|l|c|c|c|c|}
\hline Motivation & 10 & - & 6 & 8 \\
\hline In total & 36 & 25 & 48 & 51 \\
\hline
\end{tabular}

It means that each applicant for the vacant position of an insurance agent was characterized by a certain average total score, which allowed the recruiter to determine their place in the overall rating of job seekers.

Based on the collected and processed information, the Head of the structural division of «Rosgosstrakh» LLC together with the recruitment specialist made a hiring decision.

The personnel selection in «Bank DOM.RF» JSC is carried out in accordance with the scheme shown in figure 2 [2].

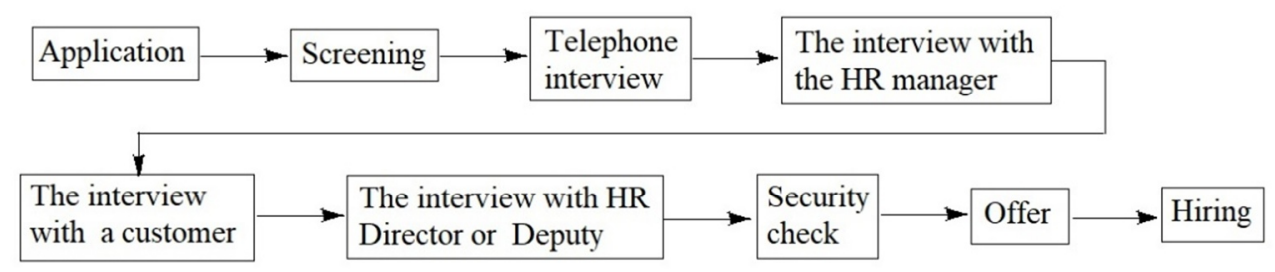

Fig. 2. Stages of hearing members of the staff «Bank DOM.RF».

At the first stage, a client, providing a job, informs a recruitment specialist about the availability of a vacancy and formulates requirements for candidates. The Head of any structural division of the company in which a vacancy is opened can act as this client or employer. This is usually done via a phone conversation, during which the client transmits to the recruitment specialist the following information:

- job title;

- the city where the vacancy is being closed;

- estimated closing date of the vacancy;

- requirements for candidates;

- official duties;

- conditions for entering the job position.

The recruiter enters all the information into the specialized program «Potok». It is a software product that allows the specialists to automate the recruitment process of any organization and get information about the results of passing all the selection stages by a candidate interested in getting a job.

A team of employees, which will take part in the selection, is formed to close any vacancy in the company. As a rule, the team consists of the client, the HR Director or the Deputy, recruitment specialists who are engaged in closing a vacancy. Among them all the responsible person stands out.

The next step is to find and add suitable job seekers to the program «Potok». The search involves the work of a recruitment specialist with the Web-sites, such as «Head Hunter», «Super Job». Applicants who appear to meet the job requirements are added to the program. Their resumes downloaded from the sites and some other information that is freely available are attached as well. Moreover, it is possible to add candidates, their resume and information about them from the Web-sites automatically.

After adding information about a job seeker to the program, the employer gets a comment with a request to read it and decide on further actions. In case of preliminary approval, the next step is a phone interview, during which the recruitment specialist informs the candidate about the open position, the requirements for the vacancy, and finds out whether the applicant is ready for the proposed list of duties. If the answer is positive, the candidate is invited to an interview with an HR- specialist. Contact information for 
communication, time and place of the interview are sent to the candidate by e-mail and duplicated in the program.

There is no approved set of questions for the initial interview. The recruitment specialist is guided by the situation and usually asks the candidate to describe their personal qualities, expectations from a new position, and reasons for dismissal from their previous job.

The result of the initial interview is either the transition of the candidate to the next stage of selection or withdrawal from the selection process, which is determined by the recruiter on the basis of the information collected and the impression made by the job seeker during the personal interview.

The next step involves an interview with the employer. It is usually performed by the Department Head, who conducts profile testing of the candidates in order to identify their knowledge and skills and to determine their compliance with the requirements of the vacant position.

The employer's approval transfers the job seeker to the stage of interview with the HRDirector, who analyzes all the information obtained about the applicant, clarifies and collects missing information, draws the candidate's attention to the specifics of the Department and the company as a whole, and to the peculiarities of the alleged duties [3].

The absence of objections from each of the parties presupposes the transition of the candidate to the next stage of selection. Applicants who successfully pass the previous stages are tested for safety. All personal data is sent to a special service that verifies the authenticity and security of the data.

At the final stage, an official document is created. This contract (called an offer) describes the terms of employment. After the document is signed by the job seeker, it is assigned the status «Accepted».

\section{Discussion}

The presented staff recruitment processes are currently used in the compnies mentioned above, which allows us to note some of their features.

As for «Rosgosstrakh» LLC, the organization presents a system for hiring specific personnel - insurance agents. On the one hand, this significantly simplifies the process, since the considered personnel can not be attributed to the management team that determines the main directions, development trends and achieved results of the company's activities. On the other hand, these are the agents who sell the company's services, thus, determine the revenue of insurance companies.

The staff selected in this case can be attributed to the mass, which is characterized by significant turnover, and the process of hiring insurance agents is a routine operation that would be logical not to simplify, but to automate. It allows the company to reduce the workload on the recruitment manager, the amount of paper documentation that accompanies the selection, and the time spent on its implementation.

Automation is possible both on the basis of a software product that accompanies the process of recruitment and evaluation of personnel, and with the help of wider use of information technologies in the considered process. For example, using video interviews, audio and chat-bots in the recruitment process [4].

As for «Bank DOM.RF» JSC, the company presents a general system of recruitment for managers and employees, thus, it is more extensive. It is carried out through a specialized software product that partially automates the selection process.

However, despite some certain advantages over the first option, often repeated fragments also attract attention. As you move from one stage of selection to another, the same information about the applicant is collected, confirmed, clarified, and verified. It turns out that each member of the selection team is busy getting virtually repetitive information 
about the candidate with slight variations, on the basis of which everyone expresses their opinion about the candidate's suitability or not. Of course, a group decision-making is always more effective than an individual decision-making, but it is logical to clearly distinguish the required information within specific stages and not to return to the same things at each subsequent stage.

Besides, the staff recruitment process of «Bank DOM.RF» JSC is characterized by three interviews with an applicant for a vacancy, in condition that they could be carried out remotely via appropriate information technologies.

\section{Conclusions}

To sum up, the recruitment systems used both in the same organization for hiring staff of different levels, and in different companies, may differ in the following parameters:

- number of selection stages;

- the content of each stage from the point of view of the techniques applied and the methods of selection;

- the number of employees of the company that provide recruitment;

- the level of development of requirements for the candidate and the vacant position;

- method of recruitment implementation, etc.

It is obvious that it is impossible to develop a common standard for the recruitment system in this case, due to the characteristics and features of companies, the selected staff, their level, the state of the labor market, the budget of the organization's personnel costs when hiring [5].

It is intertesting to note that the implementation of the hiring system is also significantly different. In the first company, a large number of documents are created to record the number of applicants, their passage through the recruitment stages, resumes, resume forms and questionnaires, and evaluation sheets. In the second organization, the data of job seekers are stored mainly in the program «Potok» in electronic form.

The use of a specialized software product in this case is more preferable because all the necessary information related to the selection of candidates for vacant positions is formed in one place and at the time of application, it is available to look through the list of open vacancies, the status of candidates participating in the selection, the members of the selection team, the opinion of team members regarding a particular candidate, etc.

The implementation of the recruitment system as in the second company has some restrictions as well.

Firstly, the number of applicants and sources of recruitment are limited by the job search Web-sites. However, the program «Potok» allows the recruiters to manually add information about the job seeker and, thus, the specified restriction cannot be considered unambiguous. But the experience of the considered company is limited only to the use of two Web-sites mentioned in the article.

Secondly, the use of a specialized software product in the company activities involves its acquisition and at least the minimum costs of the organization associated with training staff to use it.

The first restriction is determined by the recruitment implementation within a particular company, and if necessary, the sources of personnel selection can be expanded to the required boundaries [6].

The second restriction can be considered normal and inevitable in modern conditions of digitalization of company activities. Only small organizations with simple business processes can find a few arguments in favor of not digitizing. However, the companies mentioned in the article are not considered as such, and the reluctance to change the existing way of life can not be a good reason for refusing to achieve sustainable 
development of the company that is currently characterized by algorithmization of manual operations, automation of resume search and primary communication with the candidate.

\section{References}

1. N.M. Parshin, N.A. Nagibina, E.L. Kandybina, Region: systems, economy, management 1(44), 106-119 (2019)

2. E.L. Kandybina, D.A. Lyakhovskaya, Actual problems of daily activities of departments, improving the theory of organization and personnel management: Collection of articles based on the materials of the VI Scientific and practical conference «Youth readings dedicated to the memory of Yuri Gagarin» (MTRC of Air Force «Air Force Academy named after Prof. I.E. Zhukovsky and Y.A. Gagarin», Voronezh, 2019)

3. E.L. Kandybina, Problems of modern economic, legal and natural Sciences in Russia: Collection of materials of the international scientific and practical conference, 98-103 (2013)

4. N.S. Komyshov, L.N. Komyshova, Problems of innovative development of the Russian economy: Materials of the III all-Russian scientific and practical conference, 76-79 (2015)

5. O.K. Klopova, L.N. Komyshova, M. Simonova, Problems and Perspectives in Management 16(1), 214-223 (2018)

6. O.K. Klopova, L.N. Komyshova, Region: systems, economy, management 3(30), 91$98(2015)$ 